\title{
BMJ Open Tablet technology in medical education in South Africa: a mixed methods study
}

\author{
L Lazarus, ${ }^{1}$ R Sookrajh, ${ }^{2}$ K S Satyapal ${ }^{1}$
}

To cite: Lazarus L, Sookrajh $\mathrm{R}$, Satyapal KS. Tablet technology in medical education in South Africa: a mixed methods study. BMJ Open 2017;7:e013871. doi:10.1136/ bmjopen-2016-013871

- Prepublication history and additional material for this paper are available online. To view these files please visit the journal online (http://dx.doi. org/10.1136/bmjopen-2016013871).

Received 13 August 2016 Revised 27 March 2017 Accepted 31 March 2017

\section{(a) CrossMark}

${ }^{1}$ Department of Clinical Anatomy, School of Laboratory Medicine and Medical Sciences, College of Health Sciences, University of KwaZulu-Natal, Durban, South Africa

${ }^{2}$ Department of Curriculum Studies, School of Education, College of Humanities, University of KwaZulu-Natal, Durban, South Africa

Correspondence to Professor K S Satyapal; satyapalk@ukzn.ac.za, nerissa. naid0017@gmail.com

\section{ABSTRACT}

Objective The purpose of this study was to establish the use of mobile devices by learners at a selected medical school. Distribution of mobile devices was an inaugural initiative implemented by our college.

Design A mixed methodology design using a questionnaire comprising both open-ended and closeended questions was analysed from 179 (60 male; 119 female) second year medical students registered for the Anatomy course. Open-ended questions were analysed using a thematic approach by identifying emergent ideas and concepts. Close-ended questions were analysed using SPSS V.21.0.

Setting and participants Second year medical students at a medical school in South Africa.

Results Three main themes emerged, namely, (a) mobile device engagement, (b) advantages and (c) challenges affecting use of mobile devices. A majority of learners accessed their tablets for lecture notes; more females were inclined to access these devices than males. Challenges experienced included poor wifi connectivity on and off the university campus; some students were not keen on the idea of mobile devices and preferred traditional methods of teaching.

Conclusions Mobile devices have been adopted by learners at our university. Uses of technology outlined are related to Eraut's intentions of informal learning. Integrating tablets into classes had a positive effect on student access to course material.

\section{INTRODUCTION}

The last decade has seen the introduction of new technology which has transformed many aspects of our culture, commerce, communication and education. ${ }^{1}$ Mobile computing devices such as tablets, iPhones and the iPad have been swiftly implemented in many countries resulting in access to information in ways that were not possible before. ${ }^{2}$ This article begins with a brief description of mobile learning and it is proposed that the growing use of mobile technology at universities is the most current trend forcing educators to evaluate its merits.

Mobile learning is defined as 'any type of learning that takes place in learning environments and spaces that take account of the mobility of technology, mobility of learners and mobility of learning'. As mobile
Strengths and limitations of this study

- This paper demonstrates the use of mobile technology, and describes how it created new opportunities to enable positive student learning experiences in a selected university classroom.

- The use of this software application was novel in the discipline of anatomy education and was designed to enhance creativity and critical thinking and to promote increased interaction among students and faculty.

- The research sample was purposive and limited to a single cohort of second year medical degree students, which is composed largely of female students.

technology develops, it creates new opportunities for enhancing the learning experience of students at all levels of education. ${ }^{3}$ Cobcroft et at $t^{4}$ reported that 'mobile technologies are able to support learners' engagement in creative, collaborative, critical and communicative learning activities'. Traxler ${ }^{5}$ further emphasised that mobile learning offers a unique opportunity to support learning that is personalised, authentic and situated, thus facilitating a wide variety of teaching methods. The growing use of mobile technology at colleges and universities is the most current trend forcing educators to evaluate its merits and the College of Health Sciences (CHS) at our university has implemented a visual learning project and over 1400 health science students have received new Proline Tablet personal computers (PCs). This technology was the first in South Africa to provide such a platform to stream live lectures and to record lectures for later on-demand viewing. According to the Information Technology Department at the university, "the live lecture streaming incorporates an interactive classroom, where students can ask the lecturer questions electronically, and students can respond to questions, surveys and polls from their seats in the lecture room, or from a remote location. College management said this new solution opened up exciting opportunities that could even allow international 
lecturers to lecture to the student population. The new technology would allow lecturers to reach the more remote areas of the university community, proving especially beneficial to CHS students when fulfilling the clinical service requirements of their degrees" ${ }^{6}$ Mobile learning presents students and faculty with a unique opportunity to access information instantaneously, regardless of location. $^{7}$

The main advantages of using tablet technology embrace the following perceptions, namely, using software applications to enhance creativity and critical thinking and encouraging greater interaction among students and faculty. ${ }^{8}$ The benefits of using the tablet have also included a reduction in the amount of paper used and a reduction in textbook costs as students have opted for electronic versions of the text. Engagement with tablet PCs in academic programmes creates a positive educational experience. ${ }^{9}$ Miller ${ }^{10}$ reported that tablet PCs have applications that serve as study aids and productivity tools for students and students are also able to use 'apps' to help create flashcards for studying, including retrieving and editing documents on 'Google Docs' for assignments. There are hundreds and thousands of applications, some free and some requiring paid subscriptions. These applications are available in a wide range of categories and are tailored for specific medical disciplines such as Medscape, Medical Tools, Gray's Anatomy Atlas, Medical Abbreviations, Harrison's Manual of Medicine, Anatomy Learning 3D Atlas, MediApp, Resuscitation, iGyno and O\&G App. Further, some authors elaborate that the design of tablet PCs combines e-reading capabilities with web browsing, plus an assortment of applications that facilitate the integration of information by making information conveniently available, including creating a richer set of course notes. ${ }^{11} 12$

Ellaway ${ }^{13}$ categorised mobile use by medical learners into four groups, namely, (a) logistics (when learners use their devices for personal information management such as email and texting); (b) personal (when learners use their devices for social and entertainment purposes such as social media and gaming; (c) learning tools (when learners use their devices for undertaking learning tasks such as note taking and (d) learning content (when learners use their devices as a source of information such as checking drug interactions. This categorisation will used a framework to represent data later on in this paper.

\section{Anatomy in higher education}

Anatomy is an integral part of any medical degree. Within anatomy programmes, students are required to construct a comprehensive and sophisticated understanding of basic anatomy and then apply that information to clinical care. ${ }^{14}$ Anatomy requires students to learn a large volume of ancient languages based on terminology including muscle names, origins, insertions, joint, connective tissue and cellular, micro and gross anatomy. Traditionally, students use a rote or surface learning approach and have stated that anatomy is 'boring, hard, dull' in previous literature. ${ }^{15} 16$

The nature of anatomical education has transformed substantially over the past decade due to both a new generation of students who learn differently from those of the past and the explosion of advances in anatomical imaging and programming. Medical students of today are products of the 'interactive generation'. ${ }^{17}$ Millennial generation learners (sometimes referred to as digital natives) are defined as individuals whose development has been infused with technology and these individuals possess extensive experience with digital exploration, gaming and communication and are claimed to be adept with user-friendly digital devices. ${ }^{18} 19$

Anatomy teaching in medical schools has been traditionally based around the use of human cadaveric specimens, either taking the whole body specimens for complete dissection or as prosected specimens. ${ }^{20}$ The debate on teaching via the conventional pedagogy of cadaveric dissection versus the computer and more innovative modalities has raged on for the last decade. ${ }^{21}$ Those who advocate retaining this traditional learning exercise (the so-called 'traditionalists') cite the value of the cadaver experience. ${ }^{22-24}$ Those who see the practice as redundant defend their position by pointing to recent technological advancements (the so-called 'modernists'). ${ }^{25-27}$ At our university, cadaver-based learning includes the actual dissection of cadavers by medical students under the supervision of qualified instructors and the study of prosected specimens where individual structures in the human body have been dissected and displayed by skilled dissectors.

It is with this literature review in mind that the research questions addressed in this study are:

- What is the extent to which medical trainees use their mobile devices?

- What kinds of information are being accessed generally and specifically with reference to anatomical education?

\section{AIM}

The purpose of this exploratory study was to establish how learners at a selected medical school use their mobile devices since this was a unique initiative implemented by the college.

\section{MATERIALS AND METHODS Design}

A mixed methodology research design integrating both quantitative and qualitative approaches was chosen to guide our enquiry to generate the data required to meet the aims of this study.

\section{Context and participants}

The study sought to explore how learners at a selected medical school use their mobile devices. The second year class was composed of a total of 257 medical students 
registered for the Anatomy course. Of these, only 179 students (60 male; 119 female) chose to participate in this study (69.6\% response rate). The mode of anatomy instruction is composed of both lectures and practical sessions in various regional anatomical themes. There are five such themes per annum, each of which is conducted over an 8-week period. There are a total of approximately 49 hours of lectures and 197 hours of practical sessions per theme.

Students were informed about the study and their consent was duly taken for their voluntary and anonymous participation. Any chance of participant bias was eliminated by clearly explaining the objective of the study while obtaining their informed consent. There were no specific exclusion criteria and no participants withdrew from the study. Ethical approval was obtained from the University Biomedical Research Ethics Committee (BE386/15) .

\section{Instrumentation}

A survey questionnaire containing structured and free response items was used in this study to obtain both quantitative and qualitative information regarding student use of their mobile device (online supplementary appendix). Questions 1 and 2 asked all respondents about their prior exposure to mobile devices. Question 3 focused on student knowledge of participation in the college project. Questions 4-9 concentrated on type, frequency and location of usage of the tablets, including the preferred method of learning anatomy. Question 10 covered internet connectivity. Questions 11-13 and 15 asked respondents about their views pertaining to the use of the tablet in accessing anatomy content. Question 14 asked a general question related to applications accessed by students.

\section{Data analysis}

The questionnaire was administered to students before class and they were allocated $20 \mathrm{~min}$ for completion. The open-ended questions were analysed by two of the authors

\begin{tabular}{lc}
\hline $\begin{array}{l}\text { Table } 1 \\
(\mathrm{n}=179)\end{array}$ & Demographic profile of the study respondents \\
\hline Parameter & Frequency (\%) \\
\hline $\begin{array}{l}\text { Sex } \\
\text { Male }\end{array}$ & $60(33.5)$ \\
\hline Female & $119(66.5)$ \\
\hline $\begin{array}{l}\text { Population groups } \\
\text { Black }\end{array}$ & $138(77.1)$ \\
\hline Indian & $26(14.5)$ \\
White & $6(3.4)$ \\
\hline Coloured & $9(5.0)$ \\
Socioeconomic status & \\
Urban & $62(34.6)$ \\
Peri-urban & $46(25.7)$ \\
Rural & $71(39.7)$ \\
\hline
\end{tabular}

(LL and RS) using a thematic approach to identify emergent ideas and concepts expressed by participants. Key words, phrases and/or descriptions from the participants were documented, as the authors reflexively engaged with the data. Convergence and divergence of data were noted, leading to the development of preliminary emergent themes. The themes were further interrogated and developed with reference to participants' original words while also including the authors' collective interpretations. The close-ended questions were statistically analysed using the SPSS V.21.0 (SPSS). Quantitative data for comparison of categorical variables were tested using the Pearson's $\mathrm{X}^{2}$ test to compute frequency tables and descriptive statistics. A $p$ value of $<0.05$ was considered to be statistically significant.

\section{RESULTS}

\section{Sample demographics}

There were 179 respondents with a sex distribution of 60 male and 119 female students and a population grouping of 137 Black, 26 Indian, 6 White and 9 Coloured participants. (The term 'Coloured' is a historical throwback from the apartheid racial classification which remains in the post 1994 democratic era to assist the current government in seeking restitution for various disadvantaged groupings. The term 'Coloured' refers to a group of heterogeneous people, who may be more or less accurately described as 'mixed-race'. ${ }^{28}$ ) Students also indicated their socioeconomic background, namely, urban (62), peri-urban (46) and rural (71) (table 1). The average age of respondents was 20.2 years with a range between 18 and 28 years.

\section{Quantitative results}

Significant $p$ values (in bold) were recorded for the different categorical variables according to sex, population groups and socioeconomic status (table 2). The majority of students came from a rural background $(39.7 \%)$ and these students indicated that they had no prior exposure to a tablet device prior to receiving the current one as part of their course (38\%). A majority of female students $(46.4 \%)$ indicated that they had no prior access to a tablet device-these results are statistically significant $(\mathrm{p}<0.020)$ when this parameter was investigated in the sexes. Comparisons for the different population groups $(\mathrm{p}<0.000)$ and socioeconomic status $(\mathrm{p}<0.000)$ also yielded statistically significant results when this parameter was compared with students having prior access to a tablet. The majority (43.6\%) of Black students were not aware of the visual learning project and a statistically significant result $(\mathrm{p}<0.024)$ was obtained when population groups were compared with the level of student awareness of the visual learning project. A total of $35.8 \%$ of female students indicated that they used the tablet for both academic and personal reasons compared with $21.2 \%$ of male students. Overall, females tended to access their tablets for anatomy-related content more often 


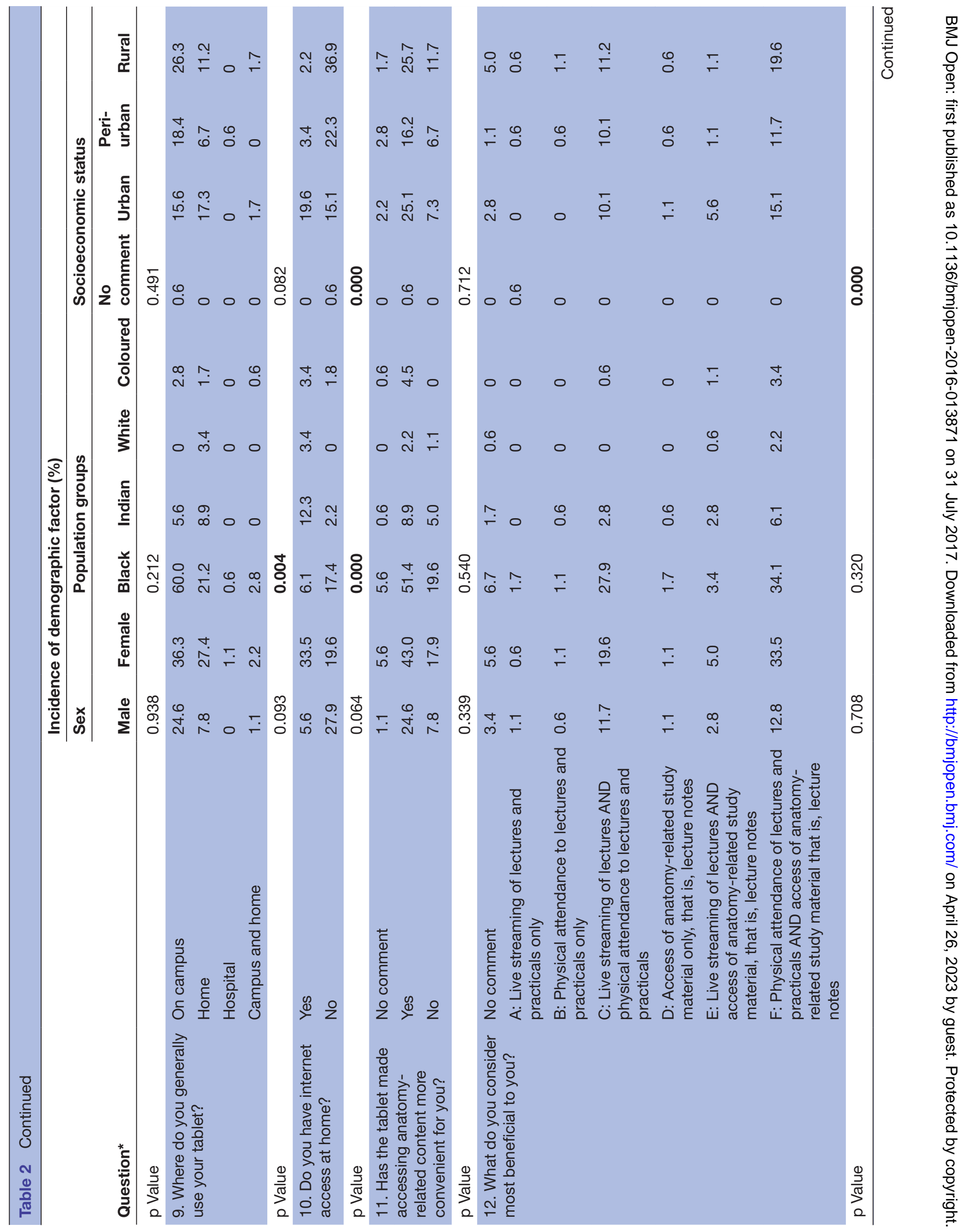




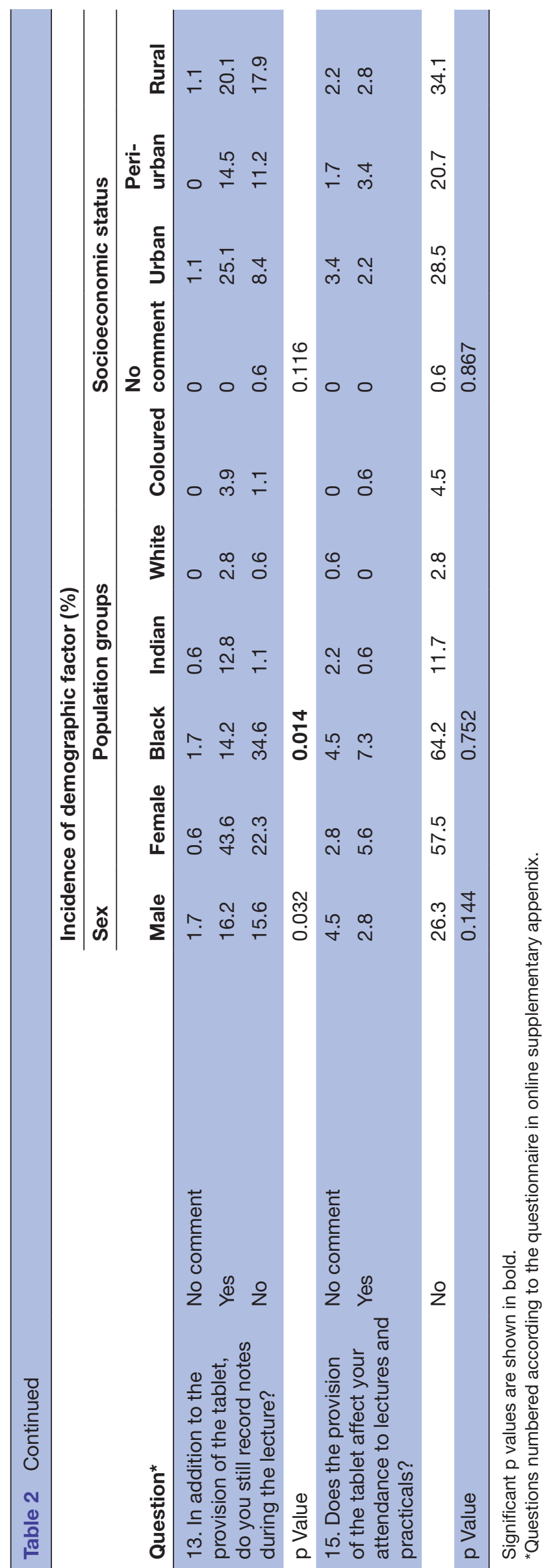

when compared with their male counterparts (table 2) which yielded a statistically significant $p$ value $(p<0.017)$. A total of $37.4 \%$ of students from rural backgrounds used the tablet to access lecture notes and a statistically significant value of $\mathrm{p}<0.000$ was obtained when socioeconomic status was compared with the latter parameter. A total of $24 \%$ of male students reported that they found physical dissection more beneficial in the study of anatomy as opposed to female students who preferred visual aids $(15.1 \%)$. A total of $62 \%$ of female students reported that they accessed the tablets for lecture notes; these students also indicated that they accessed their tablets while on campus (36.3\%). However, $17.4 \%$ of African students reported a lack of internet access at home $(p<0.000$ when population groups were correlated with internet availability). A total of $43 \%$ of female students indicated that the tablet made accessing anatomy-related content more convenient for them. A majority of female students $(33.5 \%)$ reported that they found access to anatomy-related study material, that is, lecture notes via the tablet beneficial to them versus $29.6 \%$ of male students who accessed the tablet for a similar purpose. Despite having the tablet, female students still recorded lecture notes during classroom time $(43.6 \%)$. Statistically significant correlates were recorded for sex $(\mathrm{p}<0.032)$ and population groups $(\mathrm{p}<0.014)$ versus traditional note taking. A total of $83.8 \%$ of students indicated that provision of the tablet did not affect their attendance $(57.5 \%$ female and $26.3 \%$ male) (table 2).

\section{Qualitative results}

The following themes emerged from the data, namely

i. mobile device engagement

ii. advantages of mobile devices

iii. challenges affecting use of mobile devices

iv. miscellaneous use

\section{Mobile device engagement}

Learners listed a number of uses in their engagement with mobile devices. These uses have been categorised according to Ellaway's ${ }^{13}$ four activity groups as outlined in the Introduction of this paper (table 3) as follows:

- Logistics: Students reported the use of the tablet to access emails (16.2\%) and browse the web (77\%) using internet sites such as Firefox and Google supporting.

- Personal: Students also accessed social media such as Facebook $(1.7 \%)$, social videos $(8.4 \%)$ and games $(7.3 \%)$.

- Learning tools: A large majority of the students accessed the tablet for lecture notes $(91.6 \%)$ while $26.3 \%$ of learners used applications such as WPS Office to alter documents.

- Learning content: Students also accessed sites for drug guidelines such as Medscapes (1.7\%) and 6.2\% accessed Anatomy e-books such as Netter's Interactive, Drake's Grey's Anatomy and software applications such as Essential Anatomy 2 and Visual Anatomy for learning content and expressed that they learnt 
Table 3 User engagement of learners with tablets $(n=179)$

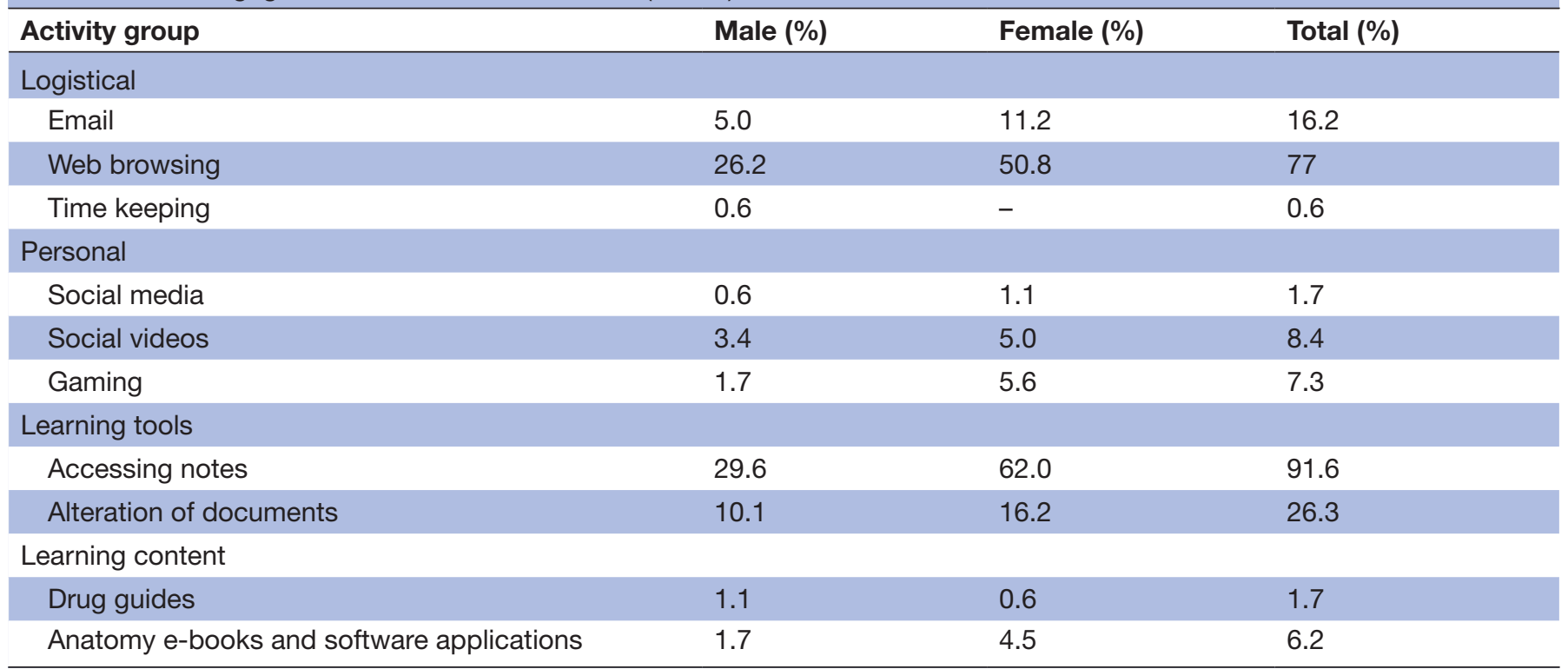

better by watching anatomy videos on the tablet as anatomical specimens are clearer in the videos and enabled them to understand the content.

Students also mentioned that the tablet allowed them to learn at their own pace $(21.2 \%)$.

The visual part, the one I use with the tablet enables me to combine what I learn in the class with what I see and it makes me able to know the exact locations of certain important structures. (Participant 1; male) (Count=31)

\section{Advantages of mobile devices}

Participants listed a number of advantages associated with the use of mobile tablets such as portability $(6.7 \%)$ allowing students the opportunity of accessing information on campus and allowing them to revise at home, access to information on the internet (22.9\%) and research areas of course content that were not covered in the lectures $(9.5 \%)$.

With visual aids, I can access the slides and videos anytime (Participant 33; female) (Count=63)

Respondents also mentioned the value of using dissection as well as visual aids in the learning of anatomy (17.3\%).

Tablet enables one to combine what is learnt in lectures with structures in the DH (Participant 21; female) (Count=6)

\section{Challenges affecting use of mobile devices}

Respondents reported on some of the challenges they experienced with the use of the tablet such as having no wifi access outside of campus $(64.2 \%)$ as well as poor wifi access on campus $(12.3 \%)$.

I do not have access to the internet at home (Participant 4; female) (Count=122)
Some also considered that learning from the tablet did not improve their understanding of anatomy $(3.4 \%)$ and felt that learning from the cadaver was easier $(60.3 \%)$ as opposed to the tablet.

The tablet does not provide visual aids of real specimens, just lecture slides. Looking at real specimens helps orientate oneself and get a three dimensional understanding. (Participant 70; female) (Count=103)

Respondents also reported on the lack of anatomy-related content being posted on the university website $(3.4 \%)$.

There are no resources for Anatomy in the UKZN Tube. (Participant 2; male) (Count=4)

\section{Miscellaneous use}

Participants also used their devices for private use such as a camera $(3.4 \%)$ and as a media player $(6.1 \%)$. Some respondents stated that the tablet has no effect on their learning at all $(11.2 \%)$.

\section{DISCUSSION}

In conducting this exploratory investigation into student perceptions of tablet usage, it was found that there are many issues to consider when using this technology in practice. The results from this study reveal that students are using mobile devices for both academic and private purposes outside of the classroom. According to Yau and Leung, ${ }^{29}$ sex differences account for one of the factors affecting students' use of technology. In this study, females were inclined to use their tablets more often than males which was statistically significant (Question 5, table 2). These results concur with that reported by Yau and Leung $^{29}$ but differ from Kekkonen-Moneta and Moneta $^{30}$; the latter authors suggested that tablet 
technology use is a more dominant activity for male students. McNulty et $a \vec{l}^{1}$ and McNulty et $a \vec{l}^{2}$ demonstrated that medical student usage of web-based, computer-aided instruction is related to sex, learning styles and personality although students may be familiar with web-based educational resources.

The majority of students $(91.6 \%)$ accessed their tablets for lecture notes. These lectures define a range of content available for web access, ranging from text files to audio or video-enhanced presentations to captured video lectures. According to Chan and Pawlina ${ }^{33}$ lecture capture records an instructor's presentation as it is delivered live in the classroom, as is the scenario at our university. Lecture capture is regarded as an effective review tool for students provided that the lecture is well presented. More than any previous mobile learning technology, tablets provide students with immediate and far-reaching access to information, course resources and real-world application of knowledge. $^{12}$

The educational practice of technology can be associated with learning theories. ${ }^{34}$ The various uses of mobile learning can be associated with the different stages in Kolb's learning cycle. ${ }^{35}$ For example, accessing the tablet for related lecture notes in the dissecting hall provides an opportunity to practice skills, social media (such as YouTube videos and Wikipedia) can assist in maintaining learners' reflections on experiences and applications which can offer access to knowledge to assist with abstract conceptualisation. $^{34}$

Bullock and Webb ${ }^{34}$ further cite the impact of technology on Eraut's theory of informal learning in the workplace as being implicit, reactive or deliberative. In this study, the so-called workplace refers to the university environment. Learning from social media is regarded as being implicit learning; reactive learning is opportunistic, often occurring in the middle of an action such as accessing the tablet "to view content and determine anatomical positions realistically (Participant 3; female)". Deliberate learning is regarded as having a goal and a set time ${ }^{36}$ where the learner clearly thinks about their actions such as accessing lecture notes for study purposes. Students reported that the immediate access to information enhanced in-class understanding of content ("...the tablet enables me to combine what I learn in the class with what I see and it makes me able to know the exact locations of certain important structures").

The qualitative data in this study corroborate the views expressed by Rossing et $a l^{12}$ particularly student responses in the themes of mobile device engagement and advantages of mobile devices.

The growing number of websites and databases further facilitate the ease with which students can 'download certain books and videos using my tablet and so it has made accessing anatomy-related content more convenient.' Some students were motivated enough to access additional anatomical content via web-based learning such as E-books, Drug Guides, Essential Anatomy 2 and
Visual Anatomy supporting the deliberative aspect of informal learning.

Hafferty $^{37}$ defines the informal mobile curriculum as those practices that 'targets learning at the level of interpersonal interactions'. Such interpersonal interactions can be found in modern anatomy curricula in learning spaces such as anatomy laboratories where students access their tablets. The deliberate engagement with the tablets in this setting allows students to access notes, videos, e-books and software applications which provide interactive visual information to augment their learning. The touch screen capabilities of the tablet allows students to enlarge or rotate images with ease, thereby making learning more hands on. ${ }^{10} 38$ Further, they provide visual representations of anatomy that more closely resemble the structures in the human body. ${ }^{7}$ This is especially beneficial in those programmes in the field of health sciences that do not possess anatomy laboratories as a component of their curriculum; hence, anatomy applications may be a useful resource for augmenting student learning.

This study's findings (“... since the tablet is portable, I am able to view lecture slides more frequently") support the literature that recommends that today's students desire and benefit from 'anywhere, anytime' learner participation. ${ }^{4}$ The literature suggests that mobile learners desire the ability and flexibility to choose their location and time for learning. ${ }^{42}$ As reported by this study, learners were allocated their own tablets; therefore, they had the option of using it for personal purposes, thus supporting Ellaway's ${ }^{13}$ logistical category of mobile device activity. Students largely accessed their tablets on campus as they experienced problems accessing wireless connectivity at home. The failure of wifi connectivity leads to disenchantment with mobile devices ("...there is no wifi") and severely hampers the learning process.

Some learners also felt that physical dissection provided the best method of learning anatomy $(30.9 \%)$, corroborating the views of authors such as McLachlan $e t a l^{39}$ and McLachlan and Patten ${ }^{40}$ despite the implementation of the newer technology, while some students felt that the provision of the tablet had no effect at all on their learning $(6.7 \%)$.

In order to maximise the benefit of mobile tablets, educators must carefully adapt the technology to specific learning goals and outcomes. Educators must not assume that students are prepared for new technologies and need to gauge student's level of knowledge and comfort with new technological devices. It is essential to devote classroom time to students to acclimate to these new devices.

\section{CONCLUSION}

Mobile computing devices have been rapidly adopted by medical learners worldwide, including those at our university as illustrated by this pilot study, and it seems 
likely that their presence will soon be ubiquitous. This study offers a unique South African perspective which has the possibility to enhance learning and also has potential problems associated with its use. We can conclude from our study that integrating tablets into higher education anatomy classes had a positive effect on student access to course material. In a subject already using active learning through traditional methods, the addition of technology via quizzes, three-dimensional visual material and access to the internet could be an alternative method of engaging students in the learning process. Students are seizing opportunities of learning anywhere, anytime due to the portability of their mobile devices.

\section{Limitations and implications for future research}

First, this study is limited by the exclusive use of the Proline 7-inch android tablet. Additional research is necessary to incorporate the use of other branded technological devices such as the Apple iPad.

Second, as this study used purposive sampling, the results may be limited by the nature of the population and cannot be generalised to account for student experiences with other academic courses offered. Additional research is necessary to isolate disciplinary strengths and weaknesses.

Third, students in graduate programmes such as those registered for medical degrees are expected to be self-directed learners who have the ability to locate resources to supplement their learning. This could be a motivating factor for students to use their tablets for learning outside of the classroom. Further studies are necessary to determine whether mobile devices such as the tablet have an impact on academic performance and assessments and whether they encourage self-directed learning. Additional studies are warranted to determine the effect of tablet technology on examination performance.

Fourth, there should be no compromise in students having access to the material they are promised; university administrators should ensure that provisions are made for technological support in places such that living residences have wifi access points for students to use at their convenience. As mobile technology continues to grow and develop, universities cannot be caught with a wireless infrastructure incapable of handling the demand for connectivity.

Contributors LL: collection, analysis and interpretation of data, drafting the article and final approval of the version to be published. RS: analysis and thematic development, revising the article and final approval of the version to be published. KSS: revising the article and final approval of the version to be published.

Funding This work was supported by the University of KwaZulu-Natal, College of Health Sciences PhD Scholarship.

Competing interests None declared.

Ethics approval Ethics approval was obtained from the Biomedical Research and Ethics Committee of the University of KwaZulu-Natal (ethics number BE386/15).

Provenance and peer review Not commissioned; externally peer reviewed.

Data sharing statement № additional data are available.

Open Access This is an Open Access article distributed in accordance with the Creative Commons Attribution Non Commercial (CC BY-NC 4.0) license, which permits others to distribute, remix, adapt, build upon this work non-commercially, and license their derivative works on different terms, provided the original work is properly cited and the use is non-commercial. See: http://creativecommons.org/ licenses/by-nc/4.0/

(C) Article author(s) (or their employer(s) unless otherwise stated in the text of the article) 2017. All rights reserved. No commercial use is permitted unless otherwise expressly granted.

\section{REFERENCES}

1. Wallace S, Clark M, White J. 'It's on my iPhone': attitudes to the use of mobile computing devices in medical education, a mixed-methods study. BMJ Open 2012;2:e001099.

2. Franko OI, Tirrell TF. Smartphone app use among medical providers in ACGME training programs. J Med Syst 2012;36.

3. Mang CF, Wardley LJ. Effective adoption of tablets in post-secondary education: recommendations based on a trial of iPads in university classes. Jite :iip 2012;11:301-17.

4. Cobcroft RS, Towers S, Smith J. Mobile learning in review: opportunities and challenges for learners, teachers and institutions. Proc Online Learning and Teaching (OLT) Conf. Brisbane: Queensland University of Technology, 2006:21-30.

5. Traxler J. Discussing and evaluating mobile learning: the moving finger writes and have writ. Int Rev Res in Open Dist. , 2007:8, 1-12.

6. UKZN website. Students Receive Tablet PCs for Visual Learning Project. http://www.ukzn.ac.za/news/2013/08/05/students-receivetablet-pcs-for-visual-learning-project (Accessed 21 July 2016).

7. Foti MK, Mendez J. Mobile learning: how students use mobile devices to support learning. J Lit Tech 2015;15:58-78.

8. Goral T. Take II Tablets. University Business 2011:46-9.

9. Mock K. Teaching with Tablet PC's. J Comp Sci Coll 2004;20:17-27.

10. Miller W. iTeaching and learning: collegiate instruction incorporating mobile tablets. Library Technology Reports 2012;48:54-9.

11. Theys MD, Lawless K, George S. Tablet computers and the traditional lecture. Frontiers in EducationFIE' 05. Proceedings 35th Annual Conference, 2005.

12. Rossing JP, Miller W, Cecil AK, et al. iLearning: the future of higher education? student's perceptions on learning with mobile tablets. JoSoTL 2012;12:1-26.

13. Ellaway $R$. The informal and hidden curricula of mobile device use in medical education. Med Teach 2014;36:89-91.

14. Ward PJ, Walker JJ. The influence of study methods and knowledge processing on academic success and long-term recall of anatomy learning by first-year veterinary students. Anat Sci Educ 2008;1:68-74.

15. Hopkins R, Regehr G, Wilson TD. Exploring the changing learning environment of the gross anatomy lab. Acad Med 2011;86:883-8.

16. Noguera JM, Jiménez JJ, Osuna-Pérez MC. Development and evaluation of a 3D mobile application for learning manual therapy in the physiotherapy laboratory. Comput Educ 2013;69:96-108.

17. Reidenberg JS, Laitman JT. The new face of gross anatomy. Anat Rec 2002;269:81-8.

18. Prensky MH. Sapiens digital: from digital immigrants and digital natives to digital wisdom. Innovate 2009;5:1-9 http://www. wisdompage.com/Prensky01.html.

19. Margaryan A, Littlejohn A, Vojt G. Are digital natives a myth or reality? University students' use of digital technologies. Comput Educ 2011;56:429-40.

20. Cahill KC, Ettarh RR. Attitudes to anatomy dissection in an irish medical school. Clin Anat 2009;22:386-91.

21. Winkelmann A. Anatomical dissection as a teaching method in medical school: a review of the evidence. Med Educ 2007;41:15-22.

22. Yeager VL. Learning gross anatomy: dissection and prosection. Clin Anat 1996;9:57-9.

23. Jones DG. Reassessing the importance of dissection: a critique and elaboration. Clin Anat 1997;10:123-7.

24. Johnson $\mathrm{JH}$. Importance of dissection in learning anatomy: personal dissection versus peer teaching. Clin Anat 2002;15:38-44.

25. Granger NA. Dissection laboratory is vital to medical gross anatomy education. Anat Rec B New Anat 2004;281:6-8.

26. McLachlan JC. New path for teaching anatomy: living anatomy and medical imaging vs. dissection. Anat Rec B New Anat 2004;281:4-5.

27. Pawlina W, Lachman N. Dissection in learning and teaching gross anatomy: rebuttal to McLachlan. Anat Rec $B$ New Anat 2004;281:9-11.

28. Elections W. Guide to the 2014 South African election. Race, ethnicity and language in South Africa. https://welections.wordpress. com/guide-to-the-2014-south-african-election/race-ethnicity-andlanguage-in-south-africa/ (Accessed 24 January 2017). 
29. Yau HK, Leung YF. Gender difference of self efficacy and attitudes towards the use of technology in learning in Hong Kong Higher Education.. Proceedings of the International Multi-conference of engineers and computer scientists Vol II, 2016:16-18.

30. Kekkonen-Moneta S, Moneta GB. E-Learning in Hong Kong: comparing learning outcomes in online multimedia and lecture versions of an introductory computing course. British Journal of Educational Technology 2002;33:423-33.

31. McNulty JA, Espiritu B, Halsey M, et al. Personality preference influences medical student use of specific computer-aided instruction (CAI). BMC Med Educ 2006;6:7.

32. McNulty JA, Sonntag B, Sinacore JM. Evaluation of computer-aided instruction in a gross anatomy course: a six-year study. Anat Sci Educ 2009;2:2-8.

33. Chan LK, Pawlina W, eds. Teaching Anatomy. A Practical Guide. Switzerland: Springer International Publishing, 2015.
34. Bullock A, Webb K. Technology in postgraduate medical education: a dynamic influence on learning? Postgrad Med $\mathrm{J}$ 2015;91:646-50.

35. Kolb DA. Experiential learning: experience as the source of learning and development. Englewood Cliffs, NJ: Prentice Hall, 1984.

36. ErautM. Informal learning in the workplace. Studies in Continuing Education 2004;26:247-73.

37. Hafferty FW. Beyond curriculum reform: confronting medicine's hidden curriculum. Acad Med 1998;73:403-7.

38. Geist E. The game changer: using iPads in college teacher education classes. Coll Stud J 2011;45:758-68.

39. McLachlan JC, Bligh J, Bradley P, et al. Teaching anatomy without cadavers. Med Educ 2004;38:418-24.

40. McLachlan JC, Patten D. Anatomy teaching: ghosts of the past, present and future. Med Educ 2006;40:243-53. 